\title{
The Effect Of Wall Opening Sizes On Unreinforced Masonry Subjected To Dynamic Loading
}

\author{
[ Trevor Neville Haas, Ph.D., Ralmar Marsh, B. Eng ]
}

\begin{abstract}
Low income unreinforced masonry structures in the southwestern region of the Western Cape Province of South Africa present a safety and economic threat if subjected to moderate intensity seismic activity. Previous experience and investigations conducted have shown the vulnerability to damage and/or collapse when these structures are subjected to moderate seismicity. Most unreinforced masonry buildings in South Africa were constructed prior to the first codified provision for seismicity contained in SABS 0160 of 1989. Numerous other residential unreinforced buildings were constructed since then. To date these types of structures have not been evaluated for South African conditions, and concerns have been expressed whether these structures conform to the new codified guidelines contained in SANS 10160-4 of 2011, which is almost a verbatim repetition of the European code for seismic design. Before an analysis of unreinforced masonry buildings can be conducted, it is imperative to determine the effect which opening have on unreinforced masonry walls. This was achieved by conducting experimental tests on four unreinforced masonry walls with various size openings, to determine its effect on the in-plane stiffness, failure frequency and failure displacement. Experimental results show that there is a relationship between the opening sizes versus the wall stiffness, failure frequency and failure displacement.
\end{abstract}

Keywords-Opening size, Unreinforced masonry, Failure frequency, Failure displacement, Dynamic loading

\section{Introduction}

Unreinforced masonry (URM) construction is the oldest building technique and is still widely used in the construction of many housing developments (Roca et al. 1998). It consists of layering bricks, blocks or stone on top of each other bonded with mortar.

\section{Dr. Trevor Neville Haas, Ph.D., Pr Eng, Pr Tech Eng}

Department of Civil Engineering, Stellenbosch University South Africa

Ralmar Marsh, B. Eng. (Former student)

Department of Civil Engineering, Stellenbosch University South Africa
The reason for its popularity is the ease of construction and can easily be constructed by unskilled workers. These buildings come in various shapes and sizes, ranging from single storey dwellings to multi storey residential buildings.

In South Africa, many URM buildings were constructed to cater for the basic needs of the increasing population but also for the resettlement of people of colour who were forcibly removed from urban areas within the city limits in accordance with the Group Areas Act of 1950, Jacobs (2013). These government housing developments in Cape Town, advanced between 1950 and 1974 (Jacobs, 2013). This area, known as the Cape Flats, comprises mainly of unreinforced masonry (URM) buildings and is the most densely populated area within the City of Cape Town in South Africa. These residential buildings consists of 3 to 5 storey URM apartment buildings with plan dimensions of approximately $50 \mathrm{~m}$ by $8 \mathrm{~m}$. These buildings were constructed prior to the previous loading code, SABS 0160 of 1989, which contained limited guidance for the analysis of buildings subjected to seismicity.

A new seismic code dedicated to seismicity, SANS 101604 of 2011, based on EN 1998-1, do not require URM buildings to be analysed against seismicity if it meets certain criteria. One of the most important requirements is that the building must not exceed 3 stories in height. Based on interaction with local government officials, we were informed that these buildings were not designed against seismicity and that a generic design was adopted for construction. It can therefore be concluded that buildings with a floor height of less than four stories would be safe during a moderate intensity earthquake.

URM structures are vulnerable to damage and/or collapse when subjected to moderate seismic activity as observed from past earthquakes. The structural robustness of URM infrastructure is also is also highly dependent on the quality of workmanship and the quality of materials used (Roca et al., 1998).

A concern was expressed whether the URM residential apartments on the Cape Flats can resist the additional forces of a moderate intensity earthquake, since this area is at risk of a 0.1g PGA (SANS 10160-4 of 2011). However, based on research by Kijko et al (2003), current investigations shows that this area is at risk to a significantly higher PGA of $0.23 \mathrm{~g}$. It is therefore important to assess whether these buildings can sustain the minimum codified requirements as well as the probable PGA of $0.23 \mathrm{~g}$ as suggested by Kijko et al (2003). Haas and van der Kolf (...) showed the catastrophic effects of a moderate intensity earthquake based on fatalities, estimated damaged caused and estimated damage based on certain countries Gross Domestic Product (GDP). 
A pilot project was thus initiated to determine whether URM infrastructure on the Cape Flats in South Africa can resist moderate intensity seismicity. Since it is impossible to subject these buildings to full scale experimental testing as well as the unknown material parameters used in South Africa, it was decided to conducted the investigation using numerical techniques. Also the effect of opening sizes in URM walls have not been well documented, especially for South Africa conditions and materials. Thus, before any numerical work could commence, it was important to determine the effect of wall openings in URM buildings to accurately conduct Finite Element simulations. Thus, the paper addresses the effect of various size wall openings in URM walls subjected to in-plane dynamic cyclic loading. The work reported here was conducted through experimental testing on a standard size URM wall with various wall size openings of $10 \%, 20 \%$ and $30 \%$, respectively.

\section{Methodology}

\section{A. Test Specimens}

Figures 1a to $1 \mathrm{~d}$ shows the four single skin walls, which are $2.0 \mathrm{~m}$ long, $1.0 \mathrm{~m}$ high and $73 \mathrm{~mm}$ wide, resulting in the walls being 15 courses in height and having 9.5 bricks in each course, used in this study. The walls were constructed using solid clay face bricks with dimensions $200 \mathrm{~mm}$ long x $50 \mathrm{~mm}$ high $\times 73 \mathrm{~mm}$ wide.

The mortar used in this study had a mix design of 1:2 (1 x $50 \mathrm{~kg}$ bag of Portland cement: 2 wheelbarrows of loose sand ratio) and had a nominal thickness of $10 \mathrm{~mm}$. To ensure consistency of the quality of workmanship, the walls were built by an experienced bricklayer employing a stretcher bond pattern. The walls were built in $3.0 \mathrm{~m}$ long x $60 \mathrm{~mm}$ high x 100 $\mathrm{mm}$ wide steel channel sections, to allow for transportation of the walls to the shaking table as well as to allow the channel to be bolted to the shaking table during testing.

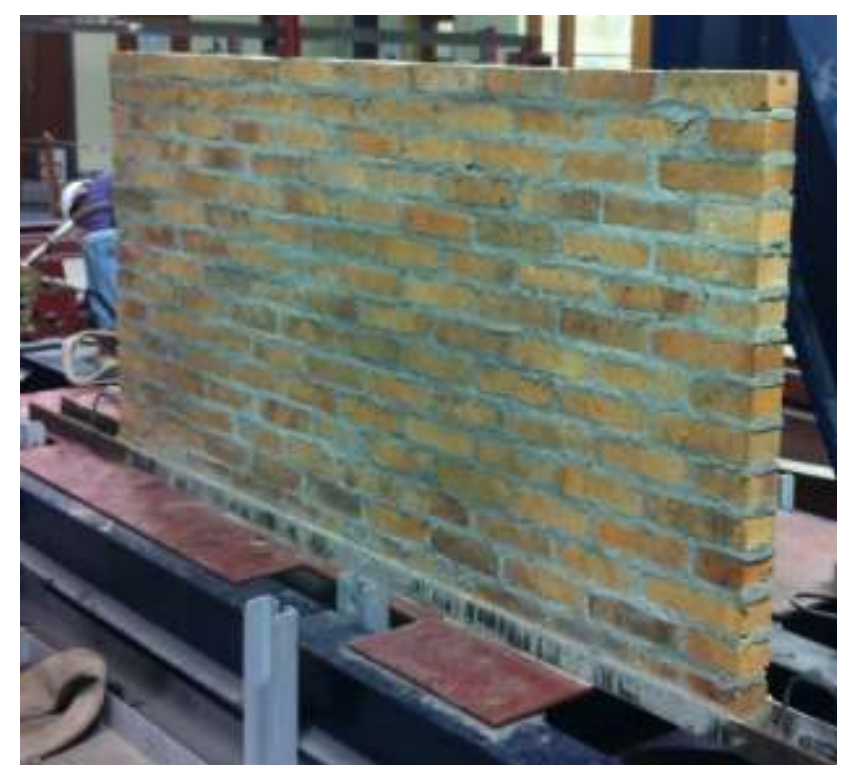

Figure 1a

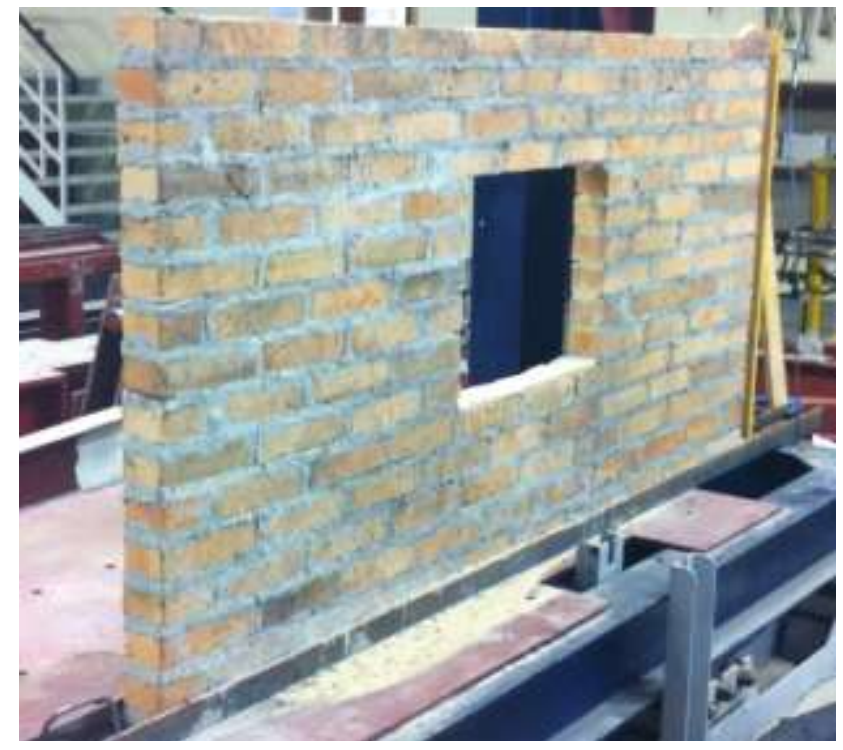

Figure $1 b$

Wall with $10 \%$ opening

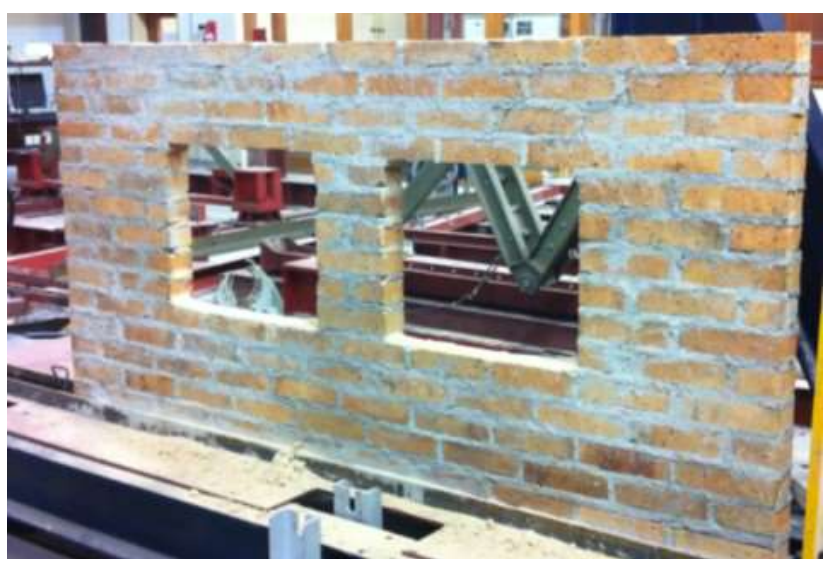

Figure 1c Wall with $20 \%$ opening

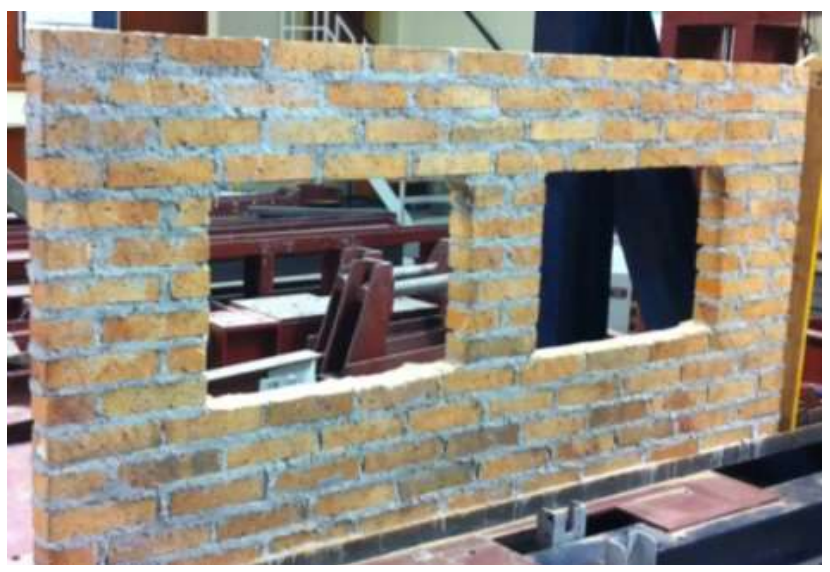

Figure 1d

Wall with $30 \%$ opening

The schematic representation of each wall is shown in Figure 2 with the relevant wall openings for the various percentage wall openings given in metres. 


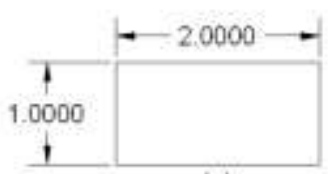

(a)

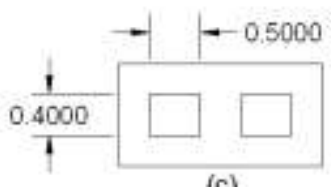

(c)

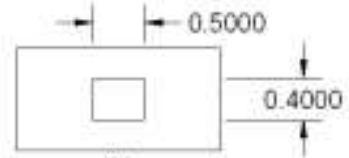

(b)

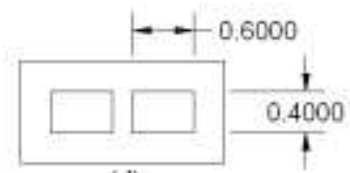

(d)
Figure $2 \quad$ Wall dimensions

\section{B. Test Setup and Instrumentation}

The test setup and loading adopted in this experimental program was designed to simulate the response that a masonry wall would experience when subjected to seismic excitation. Even though a single-storey wall does not have the complexity of a multi-storey structure, it helps to simplify the analysis and the interpretation of the results.

A horizontal cyclic load was applied in the in-plane direction of the wall using a hydraulic actuator, which was attached to the shaking table. The walls were attached to the shaking table through the channel section as shown in Figure 3. It is important to note that the walls were not stabilised in the out of plane direction during the experimental tests. An LVDT setup as shown in Figure 3 was used to measure the in-plane displacement at the apex of the walls.

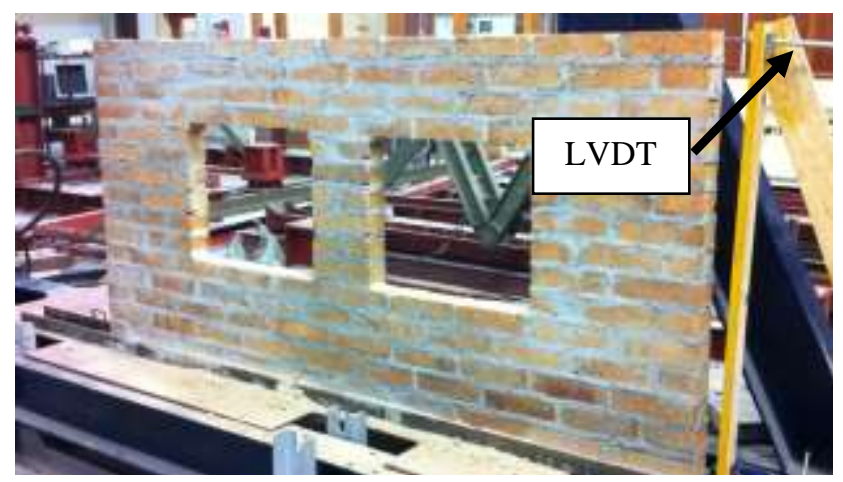

Figure $3 \quad$ Position of LVDT

\section{Loading Setup}

Each wall specimen was subjected to a constant horizontal displacement amplitude of $5 \mathrm{~mm}$ at various frequencies at the base of the shaking table through the hydraulic actuator. To simulate earthquake loading, a series of horizontal displacement cycles with increasing frequencies were applied to the base of the walls. The frequencies were increased from $0.5 \mathrm{~Hz}$ in increments of $0.5 \mathrm{~Hz}$ until a crack formed which propagated throughout the entire wall. Each wall was subjected to a frequency for a time period of 30 seconds (s) with a 10 second stability interval after each frequency to allow the wall to reach equilibrium as shown in Figure 4.

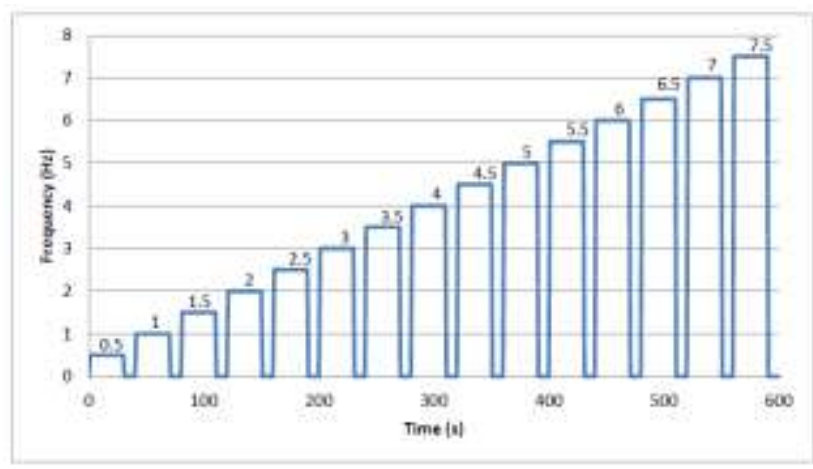

Figure 4

Position of LVDT

\section{Results and Discussion}

Prior to the commencement of the experimental tests, it was hypothesized that;

- The in-plane lateral stiffness of URM walls is directly proportional to the size of the openings in the wall.

- The in-plane failure displacement of the URM walls will increase as the size of the wall openings increase.

Hypothesis 1; The in-plane lateral stiffness of URM walls is directly proportional to the size of the openings in the wall.

The results of the experimental tests was used to validate this hypothesis. The observed failure of the walls was due to sliding shear along the toe and heel of the walls. This type of failure is common when the friction between the brick and the mortar is small. The type of clay face brick used in the experimental tests had a smoother surface compared to usual clay stock plastered bricks. The smooth surface of the clay face brick decreased the friction between the mortar and bricks causing the wall to fail in a slip plane. Furthermore, sliding shear failure is supported by research conducted by Tomazevic (1999) and Wijanto (2009).

Figure 5 illustrates the relationship between the wall opening sizes and the observed failure frequencies. A linear trend line was used to determine whether there is a correlation between the wall opening size and the failure frequency of each wall. The coefficient of determination, $\mathrm{R}^{2}$, of 0.98 indicates that there is a strong positive relationship between the wall opening size and failure frequencies. Therefore, it can be concluded that as the wall opening size increases, the failure frequency shown a linear decrease. This suggests that the lateral in-plane stiffness of the wall decreases linearly as the wall opening size increases. Based on the experimental results, we can conclude that Hypothesis 1 is therefore correct, in that the in-plane lateral stiffness of URM walls is directly proportional to the size of the openings in the wall. 


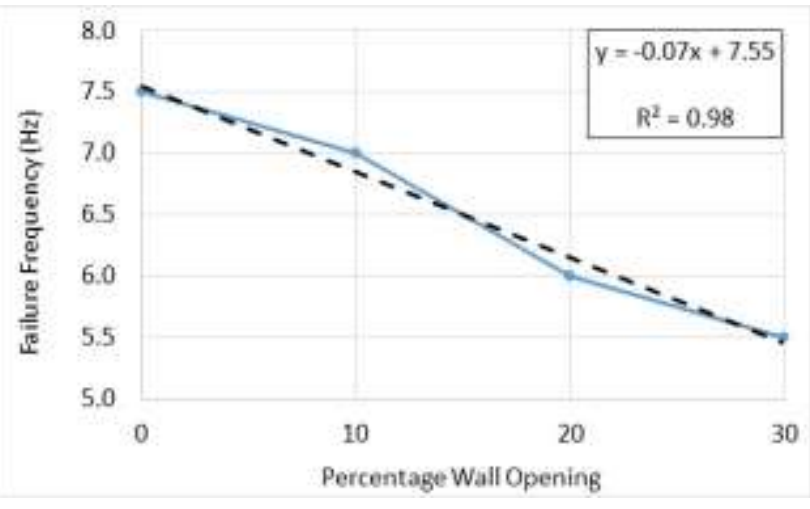

Figure $5 \quad$ Position of LVDT

Hypothesis 2; The failure displacement of the URM walls will increase as the size of the wall openings increase.

The displacement at the apex of the walls were to determine the lateral failure displacement when the wall reaches its failure frequency. This would be at the moment sliding shear occurs. Figure 6 graphically illustrates the relationship between the failure frequency and the displacement at failure of the walls.

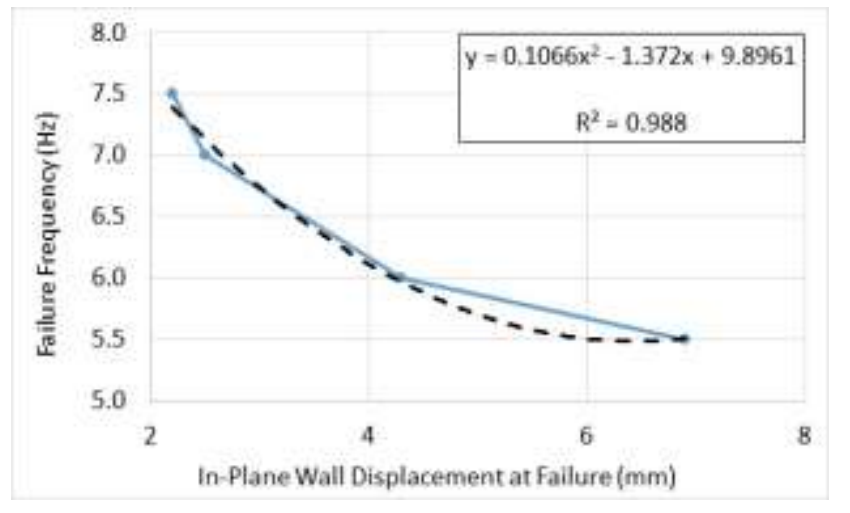

Figure $6 \quad$ Position of LVDT

The correlation between the displacement at failure and the failure frequency is extremely high when a second order polynomial used, yielding a coefficient of determination, $\mathrm{R}^{2}$, of 0.995. From Figure 6, it can be concluded that as the failure frequency increases the in-plane failure displacements of the wall decreases. The in-plane failure displacement of the solid wall of $2.2 \mathrm{~mm}$ is less than half of the in-plane failure displacement of the wall with $30 \%$ openings of $6.9 \mathrm{~mm}$. The experimental results supports Hypothesis 2 in that the in-plane failure displacement of the URM walls increases as the size of the openings increases. The results shows that the in-plane failure displacements increased non-linearly. The wall with $10 \%$ openings has a displacement of $2.5 \mathrm{~mm}$, which is not significantly different from the displacement of the solid wall with a displacement of $2.2 \mathrm{~mm}$. This could imply that walls with an opening of $10 \%$ or less can be assumed to have a stiffness that is equivalent to the stiffness of walls without any openings. Research conducted by Yanez et al. (1991) and Kabir and Kalili (2012) confirms this statement.

\section{Conclusions and Recommendations}

Based on the experimental results, solid walls can sustain higher frequencies due to their increased stiffness. The failure frequencies of the walls with an opening of $10 \%, 20 \%$ and $30 \%$ compared to the solid walls failure frequencies of $7.5 \mathrm{~Hz}$ reduces by $6.7 \%, 20 \%$ and $26.7 \%$, respectively. The difference the failure frequencies of the solid wall and the wall with $10 \%$ opening is $6.7 \%$. Therefore, we can conclude that walls with an opening of $10 \%$ or less behave similar to that as a solid wall. The same difference in failure frequencies is observed between the walls with $20 \%$ and $30 \%$ wall openings, leading to the conclusion that these walls behave in a similar manner.

The experimental results indicate that the solid walls can sustain higher frequencies at lower failure displacements. As the failure frequencies reduces, the walls become less stiff leading to an increase in the in-plane failure displacement. The in-plane failure displacement of the walls with an opening of $10 \%, 20 \%$ and $30 \%$ compared to the solid walls in-plane failure displacement of $2.2 \mathrm{~mm}$ increases by $13.6 \%, 100 \%$ and $214 \%$, respectively. Thus, the in-plane failure displacements between the solid wall and the wall with a $10 \%$ opening is negligible compared to the walls with an $20 \%$ and $30 \%$ wall opening.

The results from this study can be used in the numerical analysis of unreinforced masonry residential buildings on the cape Flats in South Africa. This information together with other experimental tests on material properties will aid in the development of a robust finite element model.

This study was conducted for walls with dimensions of $2000 \mathrm{~mm}$ long, $1000 \mathrm{~mm}$ high and $73 \mathrm{~mm}$ wide using clay face bricks. Recommendations for future studies should be conducted on;

- Concrete block with the same dimensions, as many new URM low income residential housing developments are constructed using this type of construction.

- The effect of double skin walls on the in-plane failure frequencies and in-plane failure displacements for clay stock bricks, clay face bricks and cement blocks.

- The effect of a surcharge loading on the apex of the walls.

\section{References}

[1] Roca, P., Gonzalez, J., Onate, E. and Lourenco, P., 1998. Experimental and numerical issues in the modelling of the mechanical behaviour of masonry. Structural analysis of historical constructions II.

[2] Jacobs, J., 2013. The history of Manenberg, Cape Town, South Africa. [Online] Available at: http://smirnoffchelski79.blogspot.com/2013/02/the-history-ofmanenberg-cape-town.html [Accessed 3 August 2013].

[3] SABS (South African Bureau of Standards) 1989. SABS 0160-1989. The General Procedures and Loadings to be adopted in the Design of Buildings (as Amended 1989, 1991). Pretoria: SABS Standards Division.

[4] SANS (South African National Standard) 2011. SANS 10160-4-2011. Basis of Structural Design and Actions for Buildings and Industrial 
Structures. Part 4: Seismic Actions and General Requirements for Buildings. Pretoria: South African Bureau of Standards.

[5] A. Kijko, G. Graham, M. Bejaichund, D.L. Roblin and M. B. C. Brandt, Probabilistic Peak Ground Acceleration and Spectral Seismic Hazard Maps for South Africa. Technical Report, Council of Geoscience, 2003.

[6] T. Haas and T. Kolf, "Seismic Analysis of URM Buildings in S. Africa", World Academy of Science, Engineering and Technology, International Science Index 96, International Journal of Civil, Environmental, Structural, Construction and Architectural Engineering, vol. 8, no. 12, pp. 1262-1269, 2014.

[7] Tomazevic, M., 1999, Earthquake-Resistant Design of Masonry Buildings, Series on Innovation in Structures and Construction, Volume I, Chapter 3, Masonry Materials and Construction Systems, Imperial College Press.

[8] Wijanto, L. S., 2007. Seismic Assessment of Unreinforced Masonry Walls. [Online] Available at: http://ir.canterbury.ac.nz/handle/10092/1680 [Accessed 6 August 2013].

[9] Yanez, F. V., R. Park, and T. Paulay, 1991. Seismic behaviour of walls with irregular openings. Tenth World Conference on Earthquake Engineering.

[10] Kabir, M. \& Kalali, A., 2012. In-Plane Numerical Modelling of Strengthened Perforated Masonry Walls Using FRP under Cyclic Loading. Asian Journal of Civil Engineering, 14(1), pp. 161-179.

About Author (s):

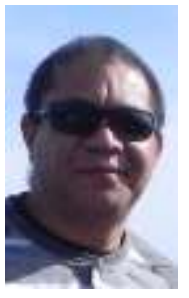

The wall opening size has an influence on the wall failure frequency and wall failure displacement depending on its size. This should be taken into account during the analysis of unreinforced masonry walls. 